\title{
No Aracy, com garra, transformando idéias em ações.
}

\author{
MARIA JOSÉ REgINATO \\ Marilda Ferraz Ribeiro de Moraes*
}

Em cada rosto, a cada gesto ou palavra dos jovens, sinto que é necessário nos organizarmos e nos unirmos para continuarmos este trabalho, a fim de resgatarmos valores, talentos, virtudes, cidadania e dignidade.

"Ações em Rede" é um projeto em que nos motivamos, trocamos experiências e nos reanimamos para continuar nossa incansável caminhada em prol das crianças e adolescentes do Cidade Aracy.

Josenil PeREIRA dA CUNHA

Liderança JoVem da Paróquia N. SRa. de Guadalupe

\section{Fruto da parceria entre a Prefeitura Municipal de São}

Carlos - Secretaria Municipal Especial da Infância e Juventude - SMEIJ e Secretaria Municipal da Educação e Cultura - SMEC, o Centro de Estudos e Pesquisas em Educação, Cultura e Ação Comunitária - CENPEC e a Fundação Volkswagen, o Projeto "Ações em Rede" começou em 2005. A opção pelo município de São Carlos, como referência-piloto de um projeto desta natureza, deve-se à determinação política da Prefeitura no atendimento a crianças e adolescentes, fazendo jus, inclusive, ao Prêmio Prefeito Amigo da Criança.

"Ações em Rede" é um projeto que visa promover a integração de ações educativas, desenvolvidas por organizações governamentais e não governamentais de um determinado território, a favor da educação e proteção integral de crianças e adolescentes, para as quais concorrem a educação escolar, considerada central no desenvolvimento da cidadania, e outros espaços de aprendizagem existentes.

Busca incentivar e fortalecer o diálogo entre a escola e outras instituições de caráter educativo, por meio de uma ação coletiva, potencializando ao máximo seus recursos e atuação, na perspectiva da construção de uma rede de base local.

\footnotetext{
* Maria josé Reginato é pedagoga e coordenadora de projetos do CEnPEC. MARILDA FerRaz Ribeiro de Moraes é pedagoga e pesquisadora do CENPEC.
}

Um projeto a favor da educação integral de crianças e de adolescentes

A Constituição de 1988 e o Estatuto da Criança e do Adolescente são instrumentos legais, conquistados pela sociedade brasileira, que reconhecem e confirmam as crianças e os adolescentes como sujeitos sociais de direitos, e atribuem, respectivamente, nos seus Artigos 4 e 227 , a responsabilidade da sua educação à família, à sociedade e ao estado, que lhes devem assegurar, com absoluta prioridade, os direitos à vida, à saúde, à educação, ao lazer, à cultura, à dignidade, ao respeito, à liberdade e à convivência familiar e comunitária.

Seguindo o mesmo princípio, a Lei de Diretrizes e Bases da Educação Nacional amplia o conceito de educação para além da educação escolar, reconhecendo o caráter socioeducativo de outros espaços públicos, governamentais e não governamentais, e sua importância para o desenvolvimento integral de crianças e adolescentes, entendido como o desenvolvimento de suas potencialidades.

Sabe-se que quanto mais acesso tiverem aos bens culturais socialmente produzidos, maiores serão as possibilidades de ampliação do repertório cultural e de níveis mais elaborados de letramento das pessoas, condições para o sucesso escolar e para o crescimento pessoal e social. Compreendemos que, somente juntando esforços entre os envolvidos, de alguma forma, com a educação de crianças e jovens, pode-se garantir a eles, como de direito, a educação mais completa possível.

\section{Uma proposta em construção}

\section{0 espaço indicado pela SMEIJ para o desenvolvimento} do projeto-piloto foi a região da Cidade Aracy, ${ }^{1}$ por ser carente e contar com alguns elementos mobilizadores, como a existência de grupos organizados: associações, ONGs, igrejas etc. ${ }^{2}$ 
Iniciaram-se, então, reuniões de concertação com ambas as secretarias - SMEIJ e SMEC - no sentido de discutir e afinar a proposta e seus respectivos princípios, pressupostos e metodologia entre os parceiros, definindo-se, ainda, critérios de adesão das demais secretarias e instituições a serem gradativamente envolvidas.

A missão primordial da Secretaria Especial da Infância e Juventude, criada em janeiro de 2005, é a integração das diversas ações de órgãos, governamentais e não governamentais, desenvolvidas no município em prol das crianças e adolescentes de nossa cidade.

Articular as inúmeras iniciativas é um grande desafio. Neste contexto, tivemos a oportunidade de trazer para São Carlos o Projeto “Ações em Rede”, objetivando a educação integral de crianças e adolescentes, entendendo que os espaços de aprendizagem, que para isso concorrem, são múltiplos. Este trabalho uniu em um território, conhecido como Grande Cidade Aracy, entidades e pessoas que ali vivem e desenvolvem ações a favor desse espaço.

Há muito a ser feito para as crianças e jovens do bairro e o “Ações em Rede" tem mostrado que não há somente carências no Aracy, mas um potencial que pode e deve ser ativado.

Pe. Agnaldo Soares lima,

SeCretário da InfânCia e JuVEntude da Prefeitura de São carlos

Como opção metodológica para a implementação do Projeto, o CENPEC propôs a constituição de duas instâncias coletivas: o Grupo Gestor e o Grupo Referência (ver quadro ao lado), das esferas central e local, respectivamente - para propiciar uma dinâmica de relacionamento ágil e flexível entre os responsáveis pelas políticas públicas e as lideranças locais, no desenvolvimento de ações integradas de atenção à criança e ao adolescente, visando à formação de uma rede de base local.

O Grupo Gestor tem caráter intersetorial, integrando representantes de diferentes secretarias da administração municipal de São Carlos, e sua função é coordenar o desenvolvimento do Projeto na cidade, mobilizando, apoiando e viabilizando as ações dos parceiros do Grupo Referência no Aracy.

O Grupo Referência é composto por lideranças de organizações governamentais e não governamentais do Cidade Aracy e tem o papel de planejar e desenvolver ações integradas entre as instituições locais, tendo como baliza as perspectivas do Projeto, de forma a otimizar os recursos existentes no bairro e na cidade, numa interação

\section{GRUPO GESTOR, GRUPO DE REFERÊNCIA E EQUIPE DO CENPEC}

Participam atualmente do Grupo Gestor as seguintes Secretarias de governo e instâncias centrais: Infância e Juventude; Educação e Cultura: representação do Sistema de Ensino, Sistema Integrado de Bibliotecas e Departamento de Cultura; Saúde; Assistência Social e Cidadania; Esporte e Lazer; Fundação Educacional São Carlos; Administração Regional do Aracy; Diretoria de Ensino Estadual: representação do Sistema de Ensino e Programa Escola da Família; Conselho Tutelar; Universidade Federal de São Carlos, Centro de Divulgação Científica e Cultural (USP) e Centro Universitário Central Paulista (Unicep).

Fazem parte do Grupo Referência as lideranças locais das seguintes instituições e serviços: Administração Regional de Saúde do Cidade Aracy; Núcleo Integrado de Saúde Cidade Aracy; Unidade Saúde da Família - Presidente Collor; Unidade Saúde da Família - Antenor Garcia; Centro de Referência da Assistência Social; Centro Comunitário Antenor Garcia; Creche Dário Rodrigues; EMEl Aracy II - Casa Azul EMEl Casa Rosa; EMEl Casa Amarela; E.M.E.F. Afonso Fioca Vitalli (CAIC); E.M.E.F. Arthur Natalino Deriggi; E.E. Dona Aracy Leite Pereira Lopes; E.E. Marivaldo Carlos Degan; E.E. Orlando Perez; GR Escola de Samba Acadêmicos do Aracy; Guarda Municipal atuante no Aracy; Polícia Militar: Projeto J.C.C. Jovens construindo a cidadania; Igreja Evangélica Avivamento Bíblico; Paróquia N. Sra. de Guadalupe; Pastoral da Criança; Projeto Associação Atlética Banco do Brasil - comunidade; Salesianos - Liberdade Assistida e Prestação de Serviço à Comunidade; TEIA - espaço de criação; Rodas de Futebol Antenor Garcia; ONG Espaço Cidadão. Integram, ainda, o Grupo Referência, todas as instituições que compõem o Grupo Gestor.

A equipe do CENPEC é composta pelos seguintes profissionais: Antonio Sérgio Gonçalves, Maria José Reginato e Marilda Ferraz Ribeiro de Moraes. 
constante e orgânica com o Grupo Gestor, procurando tecer a malha da rede pretendida.

Dada a sua natureza, a composição do Grupo Referência é bastante heterogênea, o que lhe permite expressar a diversidade presente no bairro, trazendo o colorido das diferentes necessidades e desejos dos habitantes do Aracy.

A articulação entre o Grupo Gestor e o Grupo Referência, de acordo com a metodologia adotada, acontece por meio de encontros sistemáticos e alternados entre: CENPEC e Grupo Gestor; CENPEC e Grupo Referência; Grupo Gestor e Grupo Referência.

Esse caminho metodológico, percorrido pelos dois grupos constituídos, permitiu um diagnóstico do potencial dessa região e, assim, chegar a um plano de ação comum. Esse processo de trabalho reforça e estimula a participação.

Assim, estamos buscando construir o nosso próprio caminho [...] o setor público municipal e as demais entidades presentes no território, definindo um plano de ação, exatamente para termos alternativas de aprendizagem: profissional, cultural, esportiva, ambiental e outras, com a possibilidade de construção de uma nova cidadania.

Elisete Silva Pedrazzani

Fundação Educacional SÃo CARLoS

Tecendo a malha da rede $-\mathbf{2 0 0 5}$

A idéia da constituição de uma rede de base local, direcionou, desde o início, o traçado da linha de trabalho a ser desenvolvido no Aracy, exigindo a tarefa de articular e integrar instituições e lideranças para uma ação comum, que deveria ser referendada e sustentada por princípios e pressupostos também comuns.

0 primeiro passo para isso seria o conhecimento e 0 reconhecimento mútuo de todos os envolvidos, pois ali estavam reunidas experiências muito diferenciadas e importantes, porém, desconhecidas umas das outras, embora pertencentes a um mesmo território.

Este passo foi um marco significativo que teve duas importantes conseqüências para a constituição do Grupo Referência: primeiro, representou um momento de reflexão e análise de cada instituição sobre o que faz, como faz e para que faz; segundo, produziu uma primeira sistematização do grupo, organizada em um referencial informativo importante para a construção da rede, com a relação de todas as instituições envolvidas, disponibilizada em CD-room, de fácil acesso para todos.
Outro marco importante, em 2005, foi a realização de um seminário, no final do ano, na Fundação Educacional São Carlos, que reuniu a comunidade organizada do Aracy, para discutir propostas de trabalho, visando ao atendimento das crianças e adolescentes do bairro.

0 seminário, aberto à população, contou com o apoio do poder executivo e legislativo, representados, respectivamente, pelo vice-prefeito Emerson Pires Leal, pelo secretário da Infância e da Juventude, padre Agnaldo Soares Lima, pela secretária da Educação e Cultura, professora Géria Maria Montanari Franco, e pela presidente da Câmara Municipal de São Carlos, Diana Cury, que compuseram a mesa e deram início aos trabalhos, manifestando sua visão a respeito do significado do Projeto para o município.

As professoras Isa Maria Guará, assessora da coordenação geral do CENPEC, e Elza de Andrade Oliveira, da Universidade Federal de São Carlos, tiveram papel importante na análise das propostas elaboradas pelos quatro grupos de trabalho, destacando pontos relevantes para a elaboração do Plano de Ações Integradas, na continuidade do Projeto, em 2006.

\section{6 - Onde estamos?}

A concentração de esforços do "Ações em Rede", em 2006, incidirá sobre o Plano de Ações Integradas, tanto em relação à sua elaboração, ainda em processo, quanto à implementação das ações a serem programadas, o que envolve um amplo movimento para "escutar" os habitantes do Aracy, que nos proporcionará um conhecimento mais real desse território e de sua gente.

O primeiro passo para quem deseja planejar e implantar uma política de atendimento à criança e ao adolescente no município é, sem dúvida, a análise da realidade de sua situação. Essa análise é que permitirá visualizar o que fazer primeiro, onde concentrar mais recursos, que intervenção utilizar; da mesma forma, permitirá detectar os aspectos menos agudos, ou seja, que podem esperar momento mais oportuno para uma abordagem sistemática, tanto pelo poder público quanto por organizações não-governamentais ou por uma aliança entre ambos.

Nesse sentido, será importante o resultado do censo demográfico no Aracy, abordando as condições educacionais, sócioeconômicas e de habitabilidade da população local (S.M.E.C. e Fundunesp).

JOSÉ MARIA LOUREIRO DINIZ

DIRETOR DO DEPTO. EDUCAÇÃo INFANTIL - SMEC 
No processo de elaboração do Plano de Ações Integradas, o Grupo Referência discutiu muito sobre as indicações do Seminário, definindo prioridades e princípios norteadores. Desse movimento, surgiram várias propostas que, problematizadas e reelaboradas, culminaram na atual versão do Plano, que ora apresentamos:

\section{Eixos Temáticos}

São três os eixos temáticos: formação, eventos e comunicação.

\section{Plano de Ações Integradas - 2006}

\section{Princípios norteadores:}

- Realizar ações integradas entre organizações governamentais e não-governamentais e diferentes instâncias do poder executivo estadual e municipal unitárias no bairro.

- Fortalecer e estimular a criação de vínculos e relações comunitárias no bairro.

- Promover a auto-estima e a afirmação da identidade da população.

- Criar e manter canais permanentes de comunicação entre os participantes do "Ações em Rede" e no bairro.

- Valorizar a participação da família nas atividades promovidas no bairro.

\section{FORMAÇÃO}

\section{AÇÕES}

Cursos para a formação e capacitação dos cidadãos do Aracy.

- Palestras educativas para jovens/famílias.

- Grupos de jovens, multiplicadores - jovens, formando jovens.

- Escola de circo.

\section{RECURSOS}

Voluntários / Departamento de Cultura / Escola da Família / Igrejas / Rodas de conversas entre jovens / Círculos de discussão / cursos dados pelos próprios jovens / lona e arquibancada disponíveis.

\section{EVENTOS}

\section{AÇÕES}

- Mostras, exposições, shows que evidenciem os talentos do bairro (trabalhos manuais, artesanato, música, teatro, literatura etc.).

- Eventos esportivos e culturais, seminários (seminário lúdico, seminário “Ações em Rede” e outros).

\section{RECURSOS}

- Espaço do mercado municipal e outros espaços da cidade.

- Evento de mobilização comunitária do "Ação de Cidadania".

- Festa do bairro e outras.

Otimização dos dados existentes, referentes ao bairro de Cidade Aracy.

\section{COMUNICAÇÃO}

\section{AÇÕES}

1. Ampliação dos canais de comunicação entre o "Ações em Rede" e a comunidade.

2. Levantamento e sistematização de dados considerados relevantes para o trabalho do "Ações em Rede" no Cidade Aracy:

- seminário lúdico de escuta da população;

- coleta de dados por agentes comunitários de saúde; escolas - conselho, grêmio, salas de aula nas diferentes disciplinas; estagiários da universidade;

- censo escolar - SMEC;

- dados das outras secretarias.

3. Divulgação das ações e serviços nos meios existentes.

4. Criação de um painel de informações utilitárias para os cidadãos do bairro ("Você sabia que...?").

5. Criação de uma rádio e um jornal comunitário.

6. Produção de folhetos informativos e cartazes, confeccionados pelos próprios jovens.

\section{RECURSOS}

- Encontros sistematizados do "Ações em Rede".

- Comunidade virtual do "Território Escola" - "Ações em Rede" no site do Educarede (www.educarede.org.br).

- "Escrevendo o Futuro" (CENPEC).

- Jornais e rádios da cidade.

- Folhetins/cartazes.

Otimização dos dados existentes, referentes ao bairro de Cidade Aracy. 


\section{Um olhar reflexivo sobre o Projeto}

Observando a trajetória do Projeto, ao longo do tempo, podemos vislumbrar conquistas e dificuldades.

Como o próprio nome indica, "Ações em Rede" implica o movimento articulado de pessoas, o que já traduz sua dificuldade para constituir um grupo com identidade própria e que fale a mesma linguagem e trabalhe numa direção comum. Isso demanda paciência e persistência dos integrantes, em todo o processo, pois, a adesão ao grupo ocorre em diferentes momentos, tanto para as pessoas quanto para as próprias instituições.

Respeitar o processo de cada um, acolher os recém-chegados e, ao mesmo tempo, corresponder às expectativas dos que já participam é uma aprendizagem difícil para todos nós. Por outro lado, as contingências particulares de cada participante ou instituição também provocam instabilidade na composição e freqüência do grupo. As variadas funções que cada um desempenha em sua instituição, bem como as diferenças de formação e de experiências de vida, também expressam uma diversidade com a qual o grupo precisa aprender a lidar.

Se, por um lado, são reconhecidas estas dificuldades para a constituição do grupo, por outro, o próprio processo vivido, aparentemente simples, já se configura como conquista, se considerarmos o número expressivo de instituições que aderiram ao Projeto e a criação de um amplo espaço coletivo de participação local, condição básica e essencial para o planejamento de ações integradas.
0 "Ações em Rede" é de suma importância para qualquer comunidade, não somente para o grande Aracy, pois divulga, canaliza e fortalece ações que estão sendo e que poderão ser desenvolvidas para a população menos favorecida; é através dele que as outras instituições vêem que suas contribuições, por menores que sejam, são de grande valia.

JÚlia Gomes dA SiLVA FrEITAS

Educadora da EMEl Casa Azul / Apolo PEdagógico do Projeto ASSOCIAÇÃo ATLÉtICA BANCO DO BRASIL

0 pequeno número de entidades não-governamentais que até o momento se fizeram representar no projeto pode ser um dado significativo que nos leva a pensar na necessidade de se investir na produção de capital social na região, para que a população possa contar com novos espaços de participação que ampliem ofertas educativas para suas crianças e adolescentes. 0 "Ações em Rede" espera contribuir para isso, unindo esforços para a conquista de novos parceiros e para a consolidação das parcerias estabelecidas.

A adesão definitiva das universidades locais, que recentemente participaram de encontros do "Ações em Rede" - Universidade Federal de São Carlos - UFSCAR, Universidade de São Paulo - Centro de Divulgação Científica e Cultural - CDCC e Centro Universitário Central Paulista - Unicep - será uma conquista muito importante para o Projeto, porque poderá ampliar as possibilidades de desenvolvimento de ações sistemáticas no bairro, com as contribuições que lhe são peculiares.

Há que se destacar, ainda, a gestão compartilhada do Projeto que, desde o início, permitiu a interlocução franca e afetiva entre o Grupo Gestor, o Grupo Referência e o CENPEC, dando apoio, sustentação e vida ao processo. Consideramos este o ganho mais expressivo do Projeto, uma vez que o trabalho intersetorial é um grande desafio para as políticas públicas do mundo contemporâneo, pois exige múltiplos esforços para romper com a fragmentação tradicional de nossa cultura.

A reflexão que ora fazemos sobre o que foi realizado até este momento no "Ações em Rede" nos dá clareza sobre os limites do Projeto, nas suas condições concretas, mas também nos revela suas possibilidades como uma mensagem de confiança no futuro. 


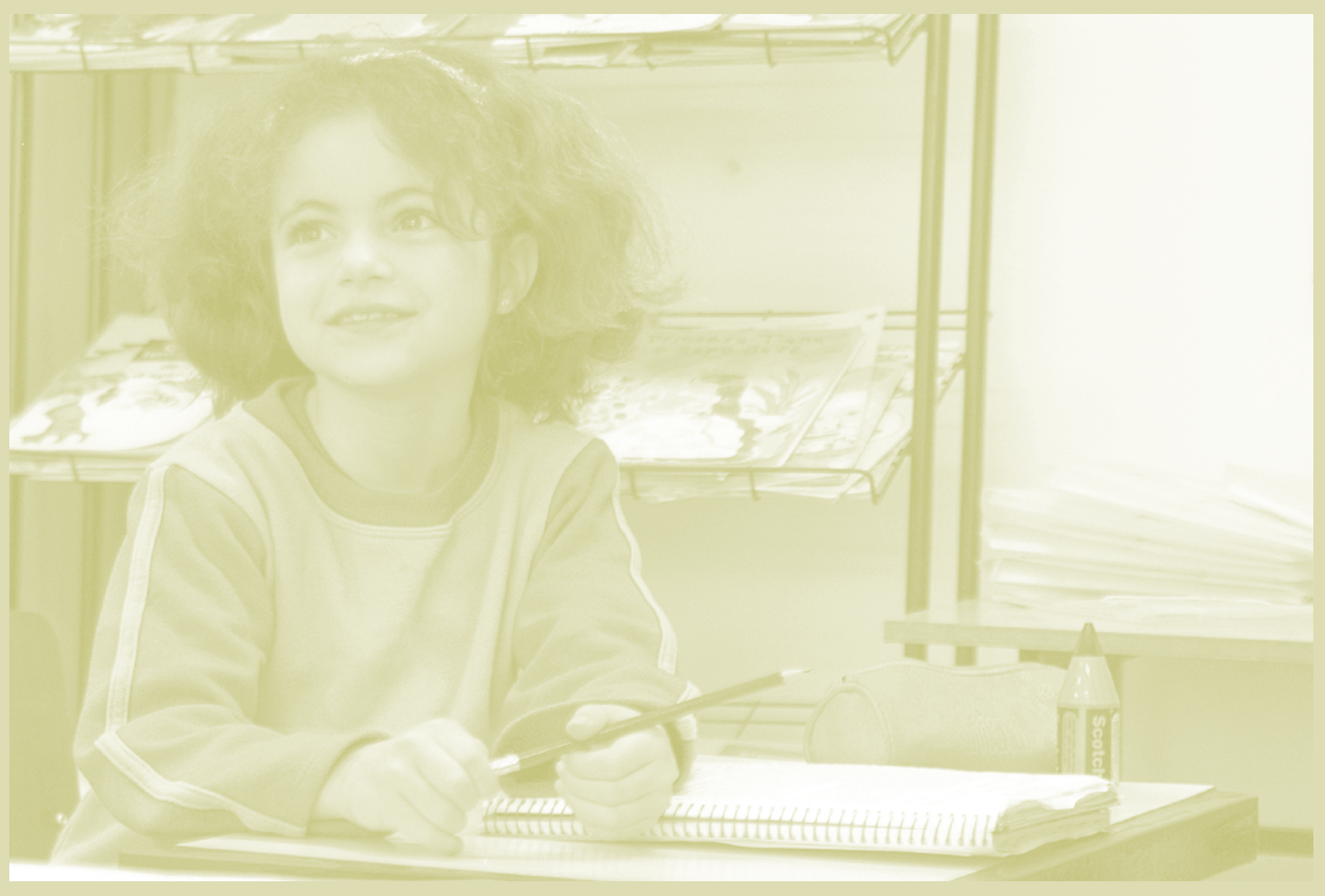

Participar do “Ações em Rede” reforça em mim a certeza de que necessito cada vez mais participar de espaços nos quais seja possível contribuir com a formação de seres humanos conscientes e dispostos a dedicar sua energia em favor da constituição de um cotidiano mais saudável e equilibrado.

Fico feliz em me ver atuando diariamente nesse sentido.

JuLIo CÉSAR PEREIRA JÚNIOR

Programa de MEdidAs SOCIOEduCATIVAS EM MEIO ABERTO

SALESIANOS - SÃo CaRLoS

\section{Bibliografia}

MELLO, Roseli Rodrigues de. Comunidades de aprendizagem: democratizando relações entre escola e comunidade. In: GT: Movimentos Sociais e Educacionais, n. 3, Agência Financiadora, Fapesp.

GUARÁ, Isa. Educação Integral. Articulação de projetos e espaços de aprendizagem, 2005 http://www.CENPEC.org.br/modules/xt_conteudo/index. php?id $=46$

Série Defesa dos Direitos da Criança e do Adolescente, n. 4, Gestão Municipal dos Serviços de Orientação à Criança e ao Adolescente, Instituto de Estudos Especiais da PUC/SP, Centro Brasileiro para a Infância e Juventude, 1995.

CARVALHO, Maria do Carmo Brant de. et alli. Desenvolvimento local. Dez. 2002. BRANCHER, Leoberto N. Visão Sistêmica da Implementação e da Gestão da Rede de Atendimento. In: MARQUES, Antônio E. S. e BRANCHER, Leoberto N. (Coord.). Encontro pela Justiça na Educação. Brasília. Fundescola/MEC 2001.

\section{Notas}

1 Trata-se de uma região 02 do Município de São Carlos, englobando os bairros Presidente Collor, Antenor Garcia e Cidade Aracy. População: 15.338 habitantes (Fonte: Orçamento Participativo - IBGE - 2000).

2 Os dados encontram-se no box da página 40. 


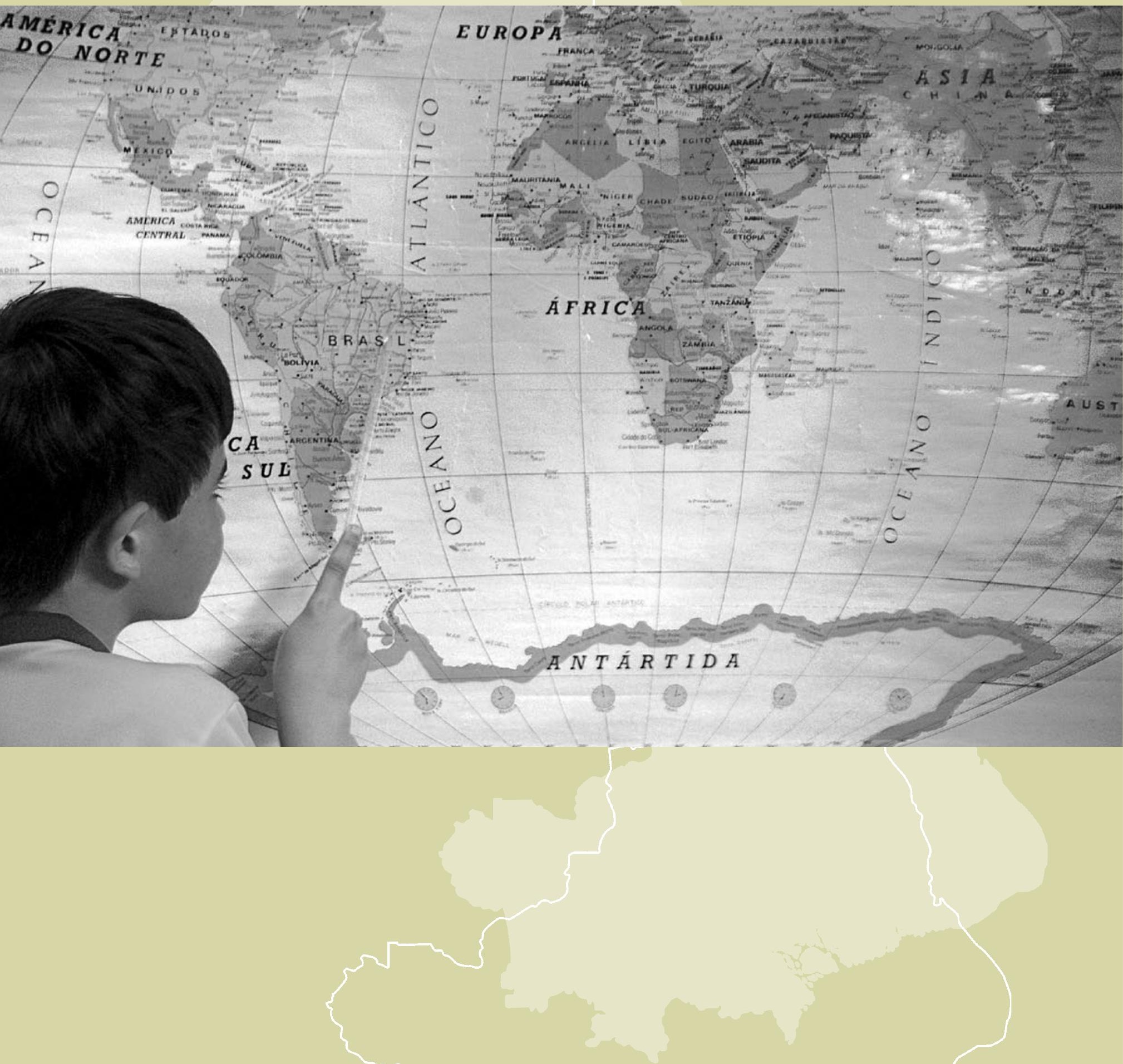

